\title{
Etchant-induced shaping of nanoparticle catalysts during chemical vapour growth of carbon nanofibres
}

Z. B. He, ${ }^{a}$ J.-L. Maurice, ${ }^{a,{ }^{*}}$ C. S. Lee, ${ }^{a}$ A. Gohier, D. Pribat ${ }^{\mathrm{a}, \mathrm{b}}$, P. Legagneux ${ }^{\mathrm{c}}$ and C. S.

$$
\text { Cojocaru, }{ }^{\mathrm{a}}
$$

${ }^{\text {a }}$ Laboratoire de Physique des Interfaces et Couches Minces, LPICM, UMR 7647, CNRSÉcole Polytechnique, Route de Saclay, 91128 Palaiseau Cedex, France

${ }^{\mathrm{b}}$ Department of Energy Science, Sungkyunkwan University Suwon 440-746, Korea

${ }^{c}$ Thales Research and Technology France, 1, Avenue Augustin Fresnel, 91767 Palaiseau Cedex, France

\footnotetext{
** Corresponding author: Tel: +331693343 44, Fax: +331693343 33,

E-mail: jean-luc.maurice@polytechnique.edu
} 
Z. B. He et al., Nickel catalyst shape

\section{Abstract}

Carbon nanofibres (CNFs) obtained by plasma-enhanced chemical vapour deposition are made of cone-shaped graphene layers, the opening angle of which has a significant influence on their properties: the smaller the angle, the closer the properties to those of carbon nanotubes. That angle is determined by the shape of the metal nanoparticle used to catalyse the growth. We show in this paper that the shape of Ni nanoparticle catalysts, and in turn the CNF properties, can be tuned during plasma-enhanced chemical vapour deposition, by the choice of the etchant gas. We show in particular that a water-containing etchant $\left(\mathrm{H}_{2} \mathrm{O}\right.$ or $\mathrm{H}_{2} \mathrm{O}+\mathrm{H}_{2}$ ) increases the growth rate by an order of magnitude at $600^{\circ} \mathrm{C}$ compared to an ammonia-containing etchant $\left(\mathrm{NH}_{3}\right.$ or $\left.\mathrm{NH}_{3}+\mathrm{H}_{2}\right)$, and leaves more elongated $\mathrm{Ni}$ particles with a cone angle three times smaller. We conclude that the cone angle and the growth rate are directly related, and propose a mechanism to explain that large difference between the two etchants. 
Z. B. He et al., Nickel catalyst shape

\section{Introduction}

Vertically aligned multi-walled carbon nanofibers (CNFs) or carbon nanotubes (CNTs) have been intensively studied over the last decade because of their numerous potential applications in field emission devices $[1,2,3,4]$, including flat-panel displays and microwave diodes[5]. Catalyst-assisted, direct-current, plasma-enhanced chemical vapour deposition (DC-PECVD) is so far the most popular technique employed to produce vertical CNTs and CNFs since it allows a precise control of alignment and density [6, 7], and it is a relatively simple and low cost growth method. The nanotubes obtained with that technique grow with the catalyst particle on top, so that growth beneath the particle remains protected, while all tendencies of non-vertical growth are immediately etched away by incoming ions. Most $3 \mathrm{~d}$ transition metals have been used to locally catalyse the decomposition of carbon-bearing radicals, thus releasing carbon atoms that fuel the growth of CNTs or CNFs. In the present paper we focus on nickel, which was the first, chronologically, to allow the DC-PECVD growth of vertically aligned nanofibres [4,5].

PECVD growth of CNTs or CNFs is usually performed in the $500-750^{\circ} \mathrm{C}$ temperature range. The mixture of gases used comprises a carbon precursor (typically a hydrocarbon gas) and an etchant gas, the latter preventing the parasitic deposition of amorphous carbon all over the sample and the poisoning of the catalysts [8]. Although CNTs exhibit better transport and mechanical properties than CNFs, it is generally CNFs that are obtained when using nickel catalyst in the above-mentioned temperature range. Thus the problem is to obtain, at a given moderate temperature, a CNF structure as close as possible to that of a CNT. The primary difference between CNTs and CNFs is the cone angle $(\theta)$ between the graphite basal planes and the tube axis $\left(\theta=0^{\circ}\right.$ for CNTs; $\theta \neq 0^{\circ}$ for CNFs) [7]. The cone angle of CNFs directly influences their conductivity as it determines the number of graphene planes that an electrical 
Z. B. He et al., Nickel catalyst shape

current will have to cross over a given distance. The cone angle and the diameter of CNFs prepared by (PE)CVD with nickel as catalyst depend on the size [9] and shape of the $\mathrm{Ni}$ nanoparticles that drive growth; more specifically, the graphene cones are quasi-replicas of the conical tails of the catalyst nanoparticles $[10,11,12,13]$ (Figure 1).

Therefore, in those processes that take place well below the melting temperature of the catalyst alloy, it is of crucial importance to study the shape and the crystallography of such catalyst particles. Catalytic growth is a dynamical process, during which the catalyst particle shape changes due to the varying compressive stress applied by the graphene planes adding one to the other in between the catalyst and the existing carbon planes [14]. Thus in-situ TEM is certainly the best way to study the growth process [15]. However, such experiments lack statistics, so that the in-situ experiments that have been performed so far mostly bring qualitative observations e.g. of the change of catalyst shape as the growth goes on $[15,16,17$, $18,19,20]$. More quantitative studies have been carried out using ex-situ scanning electron microscopy (SEM) and conventional high-resolution transmission electron microscopy (TEM) [e.g.: 4, 7, 9, 11, 21]. The crystallography of nanoparticles has been specifically addressed by several authors [10, 22, 23], and the dynamical processes of catalysis have been analysed as a function of catalyst [24]. Several reviews summarise the literature $[7,25]$. The dependence of catalyst shape as a function of growth conditions, and its influence on the form of the graphene conical sheets that make the CNFs, have been studied two decades ago by Tracz et al. [11]. These authors have observed the alignment of the graphene layers on the facets of the nickel catalysts in all the conditions they use $\left(\mathrm{H}_{2} \mathrm{O}: \mathrm{C}_{4} \mathrm{H}_{10}, 2: 1\right.$ to $8: 1,60$ mbars, temperature range $500-600^{\circ} \mathrm{C}$ ), and have showed the narrowing of the cone angle as a function of temperature [11].

In other respects, the effects of etchants on the growth of CNFs have been poorly investigated. Ammonia is currently used as the main etchant in DC PE-CVD. However, in the 
Z. B. He et al., Nickel catalyst shape

case of standard CVD, adding a small amount of water vapour to the carrier gas mix (Ar or He with $40 \% \mathrm{H} 2$ in that case) has been demonstrated to tremendously increase the growth rate in the case of Fe or Co catalysts [26]. Moreover, it has been shown to maintain the catalyst activity over a longer period of time, so that the maximum length in a given growth run could be increased by two orders of magnitude [26]. As those parameters are important for future industrial fabrication, it is of prior importance to understand and master the phenomena at the origin of these differences. Meanwhile, etchants have also been shown to influence particle shape: it has been noticed for instance that decreasing the amount of hydrogen in the growth atmosphere could diminish the cone angle of the catalyst particles [12,27,28]. The explanation given in that case was that hydrogen would saturate carbon dangling bonds at the intersections with the tube surface of the conical graphene layers: its absence would force those layers to adopt a tubular shape, which limits the density of surface dangling bonds.

The effects of the carbon precursors have been investigated by Hoffmann et al. [29] who have shown that with ammonia $\left(\mathrm{NH}_{3}\right)$ as carrier gas, acetylene $\left(\mathrm{C}_{2} \mathrm{H}_{2}\right)$ was by far the most efficient in terms of growth rate, especially compared to methane $\left(\mathrm{CH}_{4}\right)$. In the following, we thus concentrate on acetylene.

In this study we compare the effects of using either ammonia or water vapour as etchant gases, on the vertical growth of CNFs with Ni catalyst on their tips, when growth is performed by direct current (dc) plasma-enhanced CVD (dc-PECVD). Compared to ammonia, water vapour appears to accelerate the growth by at least a factor of two. Using TEM observations, we show that, whatever the carbon precursor, the cone angle $\theta$ is more than twice smaller when we use water. Those factors increase as growth temperature decreases. We also show that correlatively, the top part of catalytic particles is about bare, clean and faceted with sharp edges, after growth in water vapour. On the other hand, the catalytic particles end up covered by a few layers of graphene and rounded in shape in the case of 
Z. B. He et al., Nickel catalyst shape

growth in ammonia. We discuss the implications of these differences in terms of carboncatalyst contact and its effects on the mobility of carbon atoms across the catalyst particle during growth.

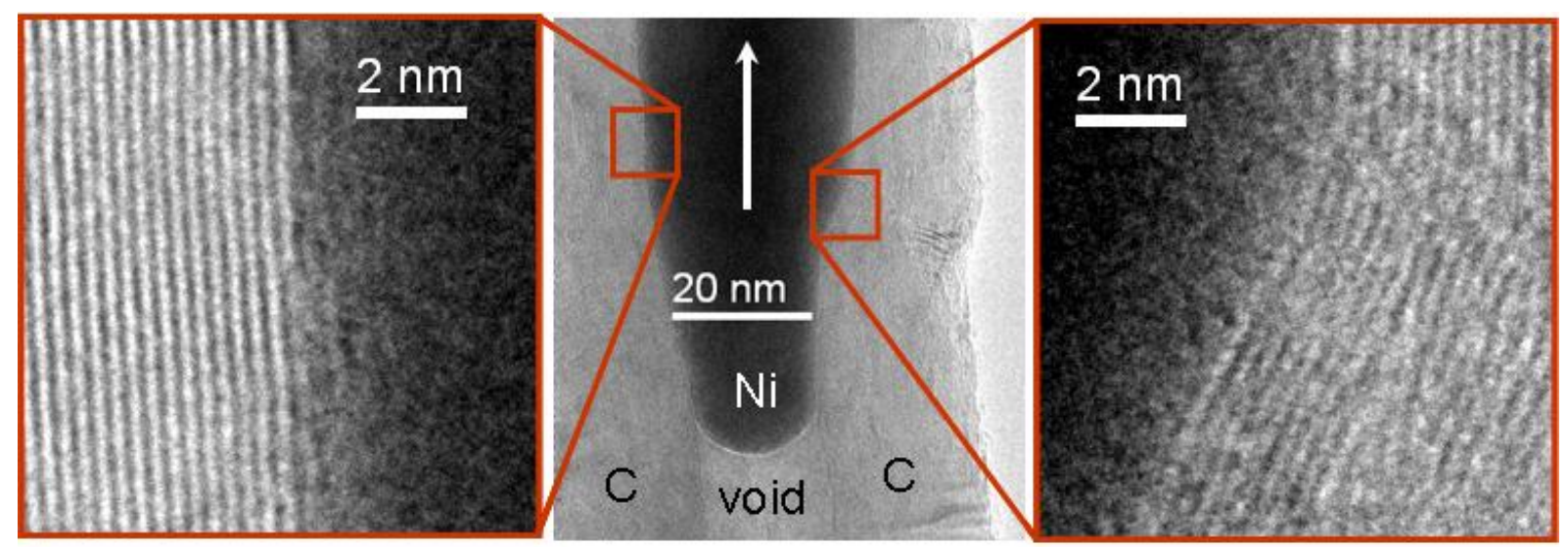

Figure 1. (a) High-resolution TEM image of the head of a nanofibre grown at $650^{\circ} \mathrm{C}$ in $\mathrm{C}_{2} \mathrm{H}_{2}$ : $\mathrm{H}_{2} \mathrm{O}$ showing how the cone-like graphene layers duplicate the shape of the tail of the catalyst nanoparticle. The arrow indicates the growth direction. Note that graphene-plane nucleation (left-hand side enlargement) may take place at nickel surface steps that are upside oriented, contrary to expectations.

\section{Experimental details}

\subsection{Growth}

Vertically aligned CNF arrays were grown from Ni catalysts originating from thermally evaporated thin films with different thicknesses. Si substrates were used, either bare or covered with a TiN diffusion barrier layer. Growth was performed by dc PECVD from 600 to $670{ }^{\circ} \mathrm{C}$, in a gas mixture including either methane $\left(\mathrm{CH}_{4}\right)$, or acetylene $\left(\mathrm{C}_{2} \mathrm{H}_{2}\right)$ as carbon precursor gases and water (either $\mathrm{H}_{2} \mathrm{O}$ or $\mathrm{H}_{2}: \mathrm{H}_{2} \mathrm{O}, 2: 1$, by volume) or ammonia (either $\mathrm{NH}_{3}$ or $\mathrm{NH}_{3}: \mathrm{H}_{2}, 2: 1$ ) as etchant gases. The gas flows were precisely controlled to avoid the generation 
Z. B. He et al., Nickel catalyst shape

of amorphous carbon on the surface of catalysts. In order to obtain well aligned CNFs, the applied voltage between anode and cathode in the chamber was kept constant at $500 \mathrm{~V}$, with a current intensity of $0.2 \mathrm{~A}$. The extraction voltage and the current were slowly increased up to the optimum conditions at the beginning of the growth process. At the end of the growth process, the chamber was totally pumped out and cooled down. Cooling took around 60 minutes without any gas flowing in the growth chamber. The length of CNFs was controlled by the growth time and their average diameter by the thickness of the starting $\mathrm{Ni}$ film.

Starting from a continuous Ni film, it takes two stages to grow CNFs: (1) de-wetting of the film, in order to form $\mathrm{Ni}$ nanoparticles and initiate the nucleation of several graphene layers between those particles and the substrate, and (2) growth of the nanofibers from the Ni nanoparticles, fuelled by the decomposition of the carbon precursor on the exposed surface of those particles. As the two etchants yielded different particle sizes for a given thickness of the starting $\mathrm{Ni}$ thin film (larger with $\mathrm{NH}_{3}$, this will be published elsewhere), we have also prepared some samples with the same $\mathrm{H}_{2}: \mathrm{H}_{2} \mathrm{O}$ etchant during the de-wetting stage, and a switch (or not) to $\mathrm{NH}_{3}$ only during the growth stage, so that the Ni-particle size be the same in the two cases. We also switched to $\mathrm{NH}_{3}$ at various stages of growth, and could verify it was possible to benefit from the high growth speed of $\mathrm{H}_{2} \mathrm{O}$, and from the protective coating of nickel provided by $\mathrm{NH}_{3}$.

\subsection{Characterisation}

The CNFs were observed using a Hitachi S-4800 FE-scanning electron microscope (SEM) with $25 \mathrm{kV}$ accelerating voltage. The microstructure of the CNFs and Ni catalysts was studied by TEM using a Philips CM 30 electron microscope working at $300 \mathrm{kV}$, and a Topcon 002B microscope working at $120 \mathrm{kV}$ or $160 \mathrm{kV}$. TEM samples were obtained by scratching deposits over holey amorphous carbon membranes. However, this substrate had the drawback 
Z. B. He et al., Nickel catalyst shape

of oxidising the samples under the beam (see below). Other details on the TEM procedure are given in the Supplementary Data. We have also prepared cross-sections made from sandwichtype samples, after sliding one part of the sandwich with respect to the other, so that the nanofibres lie parallel to the substrate and along the optical axis of the microscope. This allowed us to obtain cross sections of nanofibres perpendicular to their axes.

\subsection{Electron beam damage}

Electron beam irradiation is a significant issue when observing carbon nano-objects with TEM. While the knock-on threshold energy for a carbon atom in a nanotube is about $86 \mathrm{keV}$ [30], observations remain possible at higher energies provided that the total dose (settings plus recordings) remains small. However, knock-on is not the only source of defects. Figure 2 shows that another source of damage is electron beam heating of the metal nanoparticle, which significantly modifies its surface, whatever the accelerating voltage or the microscope used. Except for those of Figure $2 \mathrm{~d}-\mathrm{f}$, all of the TEM images presented in this paper were recorded with nanofibres deposited on holey amorphous carbon TEM grids from Oxford Instruments. The Ni particles on such a substrate appeared to oxidize under the beam. This sensitivity had a consequence on characterisation: it was hardly possible to determine at the same time the microstructure of a surface and its orientation, as tilting the sample along a zone axis (convenient for surface characterisation) generated an irradiation that completely oxidised the surface. This is why our zone-axis images always exhibit surface oxide, while our images used to analyse the nature of surfaces, recorded as fast as possible, are not oriented along zone axes. This is why, in turn, and quite unfortunately, we present no high resolution images of the surfaces. 

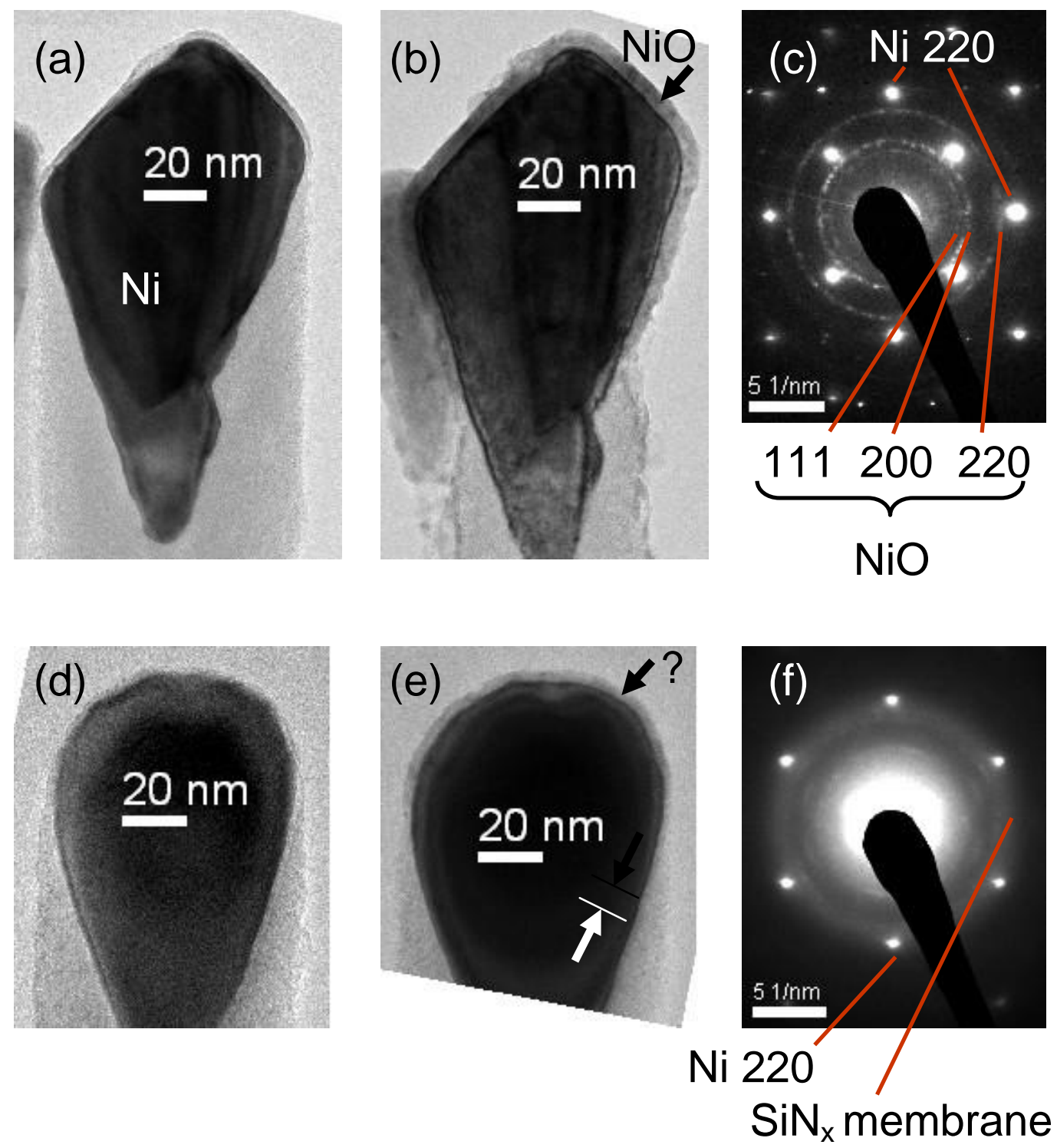

Figure 2. Comparison of the effects of electron irradiation when nanofibres are deposited on a holey carbon membrane (a-c), and on an amorphous SiNx membrane (d-e). Both CNFs were grown in the same run at $650^{\circ} \mathrm{C}$, with $\mathrm{NH} 3: \mathrm{C} 2 \mathrm{H} 2$. Irradiation at $160 \mathrm{kV}(\mathrm{a}-\mathrm{c})$ or $120 \mathrm{kV}$ (d-f), for $\sim 1$ min. (a, d) and $\sim 15 \mathrm{~min}$. (b-c, e-f). The orientation is random before irradiation, and along $<110>(\mathrm{b}, \mathrm{c})$ and $<111>(\mathrm{e}, \mathrm{f})$ zone axes of $\mathrm{Ni}$ after irradiation (tilt due to operator). A capping layer develops upon electron irradiation in both cases. The selected area diffraction pattern exhibits corresponding rings characteristic of fcc $\mathrm{NiO}$ in the case of the holey carbon membrane (c), and of a classical amorphous carbon contamination in the case of the SiNx membrane (f). 
Z. B. He et al., Nickel catalyst shape

It is interesting to note that the oxidation did not occur when using a thin silicon nitride membrane as substrate, on which we only observed the growth of a standard contamination film (Figure 2d-f). Silicon nitride had other drawbacks like charging and difficulty to deposit the CNFs on it, so that we did not use it except for this test. The oxygen thus comes from the amorphous carbon membrane. Selected area diffraction (Figure 2c) shows that the oxide obtained on the holey carbon grid has indeed the structure of fcc $\mathrm{NiO}$.

\section{Structure of catalyst particles}

The crystallography of the Ni particles appears quite simple: they are all single crystals, and all of the standard fcc phase of Ni. We distinguish no effect of the growth atmosphere on crystallographic features, other than the surface faceting we discuss in sec.4. Characterising the crystallographic direction of growth is not a simple task because of projection artefacts (see Supplementary data, fig. S1, and ref. [31]). When it can be determined, the growth axis exhibits low indices, quite generally $\langle 110\rangle$, confirming previous observations [22,23], but sometimes $\langle 100\rangle,\langle 111\rangle,\langle 211\rangle$. It is interesting to note, however, that the present $\langle 110\rangle$ oriented nanoparticles rarely have $\{110\}$ top facets (see e.g. Figure 3, see a rare exception in Supplementary information, fig. S1), which will be discussed in the next section. Twinning may occur, with a frequency that seems to depend rather on the temperature and the carbon precursor used than on the etchant, so that we will not discuss it in the present work; the twin plane may lie parallel to the $<110\rangle$ growth direction, or at an angle with it. Let us add that it does not appear to influence the contact plane between particle and nanofibre, and only slightly the top surface faceting [31]. 
Z. B. He et al., Nickel catalyst shape

(a)

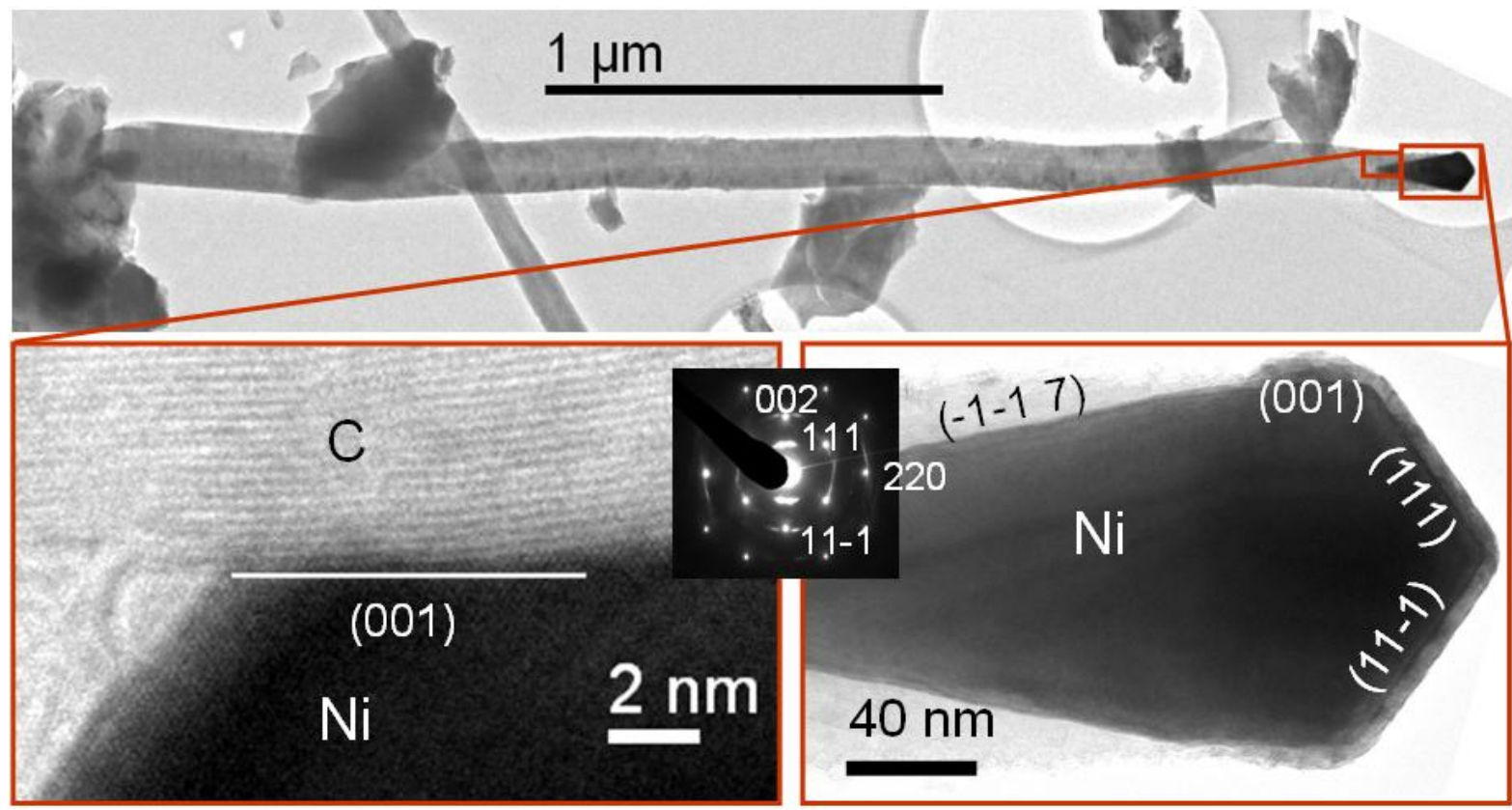

(b)

Figure 3. TEM images of a CNF grown at $675^{\circ} \mathrm{C}$ with $\mathrm{H}_{2}: \mathrm{H}_{2} \mathrm{O}: \mathrm{C}_{2} \mathrm{H}_{2}$ after it has been carefully tilted to reach the [1-10] zone axis where catalyst facets are parallel to the beam (a NiO layer has developed during this procedure, see Figure 2). (b) Lateral facets are almost parallel to the wire axis, and $\{100\}$ oriented; top facets are along $\{111\}$ planes; facets parallel to the graphene planes on the tail are poorly defined with high indices. This part of the catalyst is actually close to that of a truncated cone (see Figure 7). The diffraction pattern in inset indicates that the nanoparticle is [110] oriented. (c) Atomic-scale detail of the graphite-catalyst interface, showing the absence of correlation between graphene layers and Ni lowindex atomic planes.

\section{Shape of catalyst particles}

\subsection{Preliminary observations}

Figure 4 shows typical SEM images of CNFs obtained when starting with a 10-nm thick nickel film: they are well aligned and oriented perpendicular to the substrate. The CNFs in that case were grown on a patterned substrate designed for field emission (TiN/Si) [32], at 
Z. B. He et al., Nickel catalyst shape

$600{ }^{\circ} \mathrm{C}$ for $30 \mathrm{~min}$, using acetylene as carbon precursor, and either hydrogen-water

$\mathrm{C}_{2} \mathrm{H}_{2}: \mathrm{H}_{2}: \mathrm{H}_{2} \mathrm{O}(5: 10: 5)$ (Figure 4a,b) or hydrogen-ammonia $\mathrm{C}_{2} \mathrm{H}_{2}: \mathrm{H}_{2}: \mathrm{NH}_{3}(8: 10: 18)$ (ratios in sccm) (Figure 4c) as etchant gases. Each CNF has a uniform diameter from bottom to top. As in other works, the present Ni-catalyst particles on the top of CNFs have inversed water drop shape, elongated along the CNF axis. They can be separated into two well-defined parts: a bulky top part facing the plasma, the "head", and a thinner bottom part surrounded by the beginning of the nanofibre, the "tail". In Figure 5, the head exhibits clearly defined facets in the case where water was used as etchant, and rounded shapes in the case of ammonia. We analyse those features in detail in the next section.

What is particularly remarkable in Figure 4 is the difference of size of the nanofibres in the two sets: during a growth treatment of the same duration, the use of water vapour leads to nanofibres that are about an order of magnitude longer than those made with ammonia.

\subsection{Faceting of catalyst head}

The most noticeable feature of the catalyst particle head is faceting, clearly visible and sharp in the case where hydrogen-water has been used as etchant, and non-apparent in the case of ammonia. However, a refined analysis reveals that the latter samples also have facets, but with smooth edges (see e.g. Figure 2 a, b), so that what differentiates the two kinds of samples is the sharpness $\left(\mathrm{H}_{2} \mathrm{O}\right)$ or roundness $\left(\mathrm{NH}_{3}\right)$ of edges rather than the presence or absence of facets. To analyse facet orientation, we restrained our study to the $\mathrm{H}_{2}: \mathrm{H}_{2} \mathrm{O}$ samples where it is easily visible. The results we present here are complementary to those we have published separately [31]. On average, facets systematically correspond to low-index planes, mostly $\{111\}$ and $\{100\}$ (Figure 3, Figure 5 and Figure 6), and less often $\{110\}$ (see Supplementary data, fig. S1). These correspond in turn to low surface energies, which will be discussed in sec. 5 . 


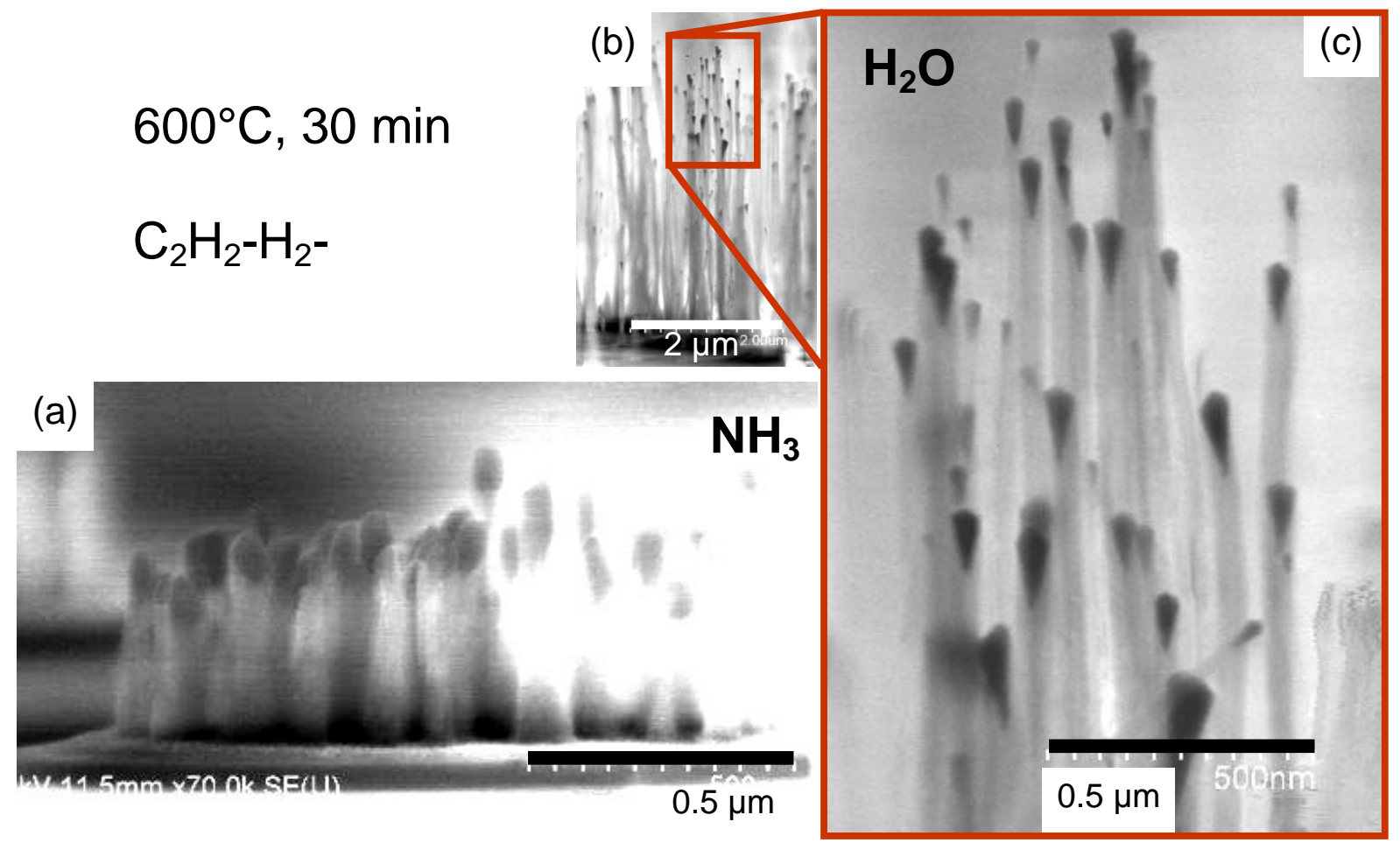

Figure 4. SEM images of vertically aligned top-type CNFs grown for $30 \mathrm{~min}$ at $600^{\circ} \mathrm{C}$ in $\mathrm{C}_{2} \mathrm{H}_{2}: \mathrm{H}_{2}: \mathrm{X}$ on a 10-nm Ni film deposited on SiN/Si. The etchant $\mathrm{X}$ was $\mathrm{NH}_{3}$ (a) or $\mathrm{H}_{2} \mathrm{O}(\mathrm{b}, \mathrm{c})$. The average CNF length is $3.5 \mu \mathrm{m}$ in the case of $\mathrm{H}_{2} \mathrm{O}$ and $0.4 \mu \mathrm{m}$ in the case of $\mathrm{NH}_{3}$. The $\mathrm{Ni}$ particles have facets in the case of $\mathrm{H}_{2} \mathrm{O}$, and rounded shapes in the case of $\mathrm{NH}_{3}$. 
Z. B. He et al., Nickel catalyst shape
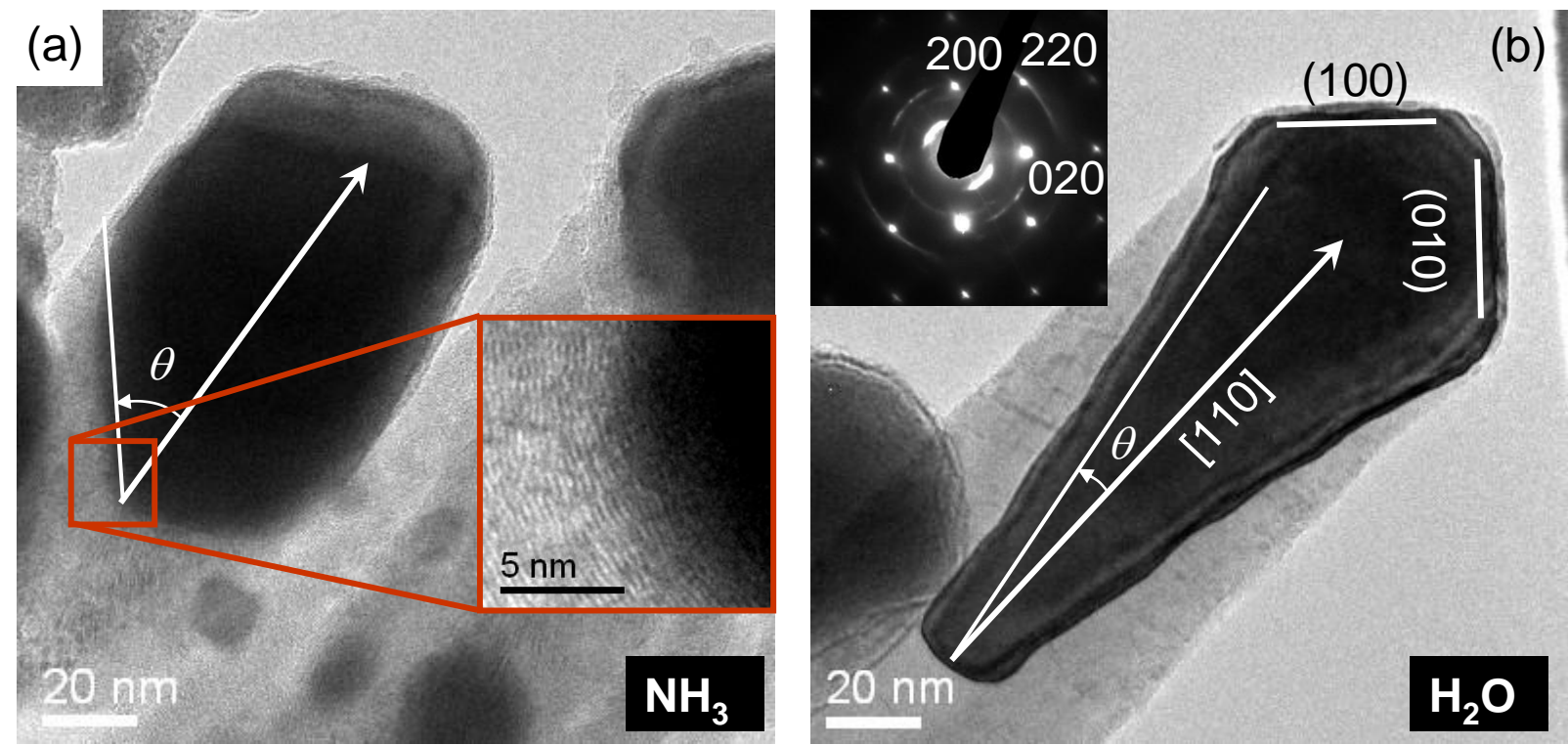

Figure 5. TEM images of the CNFs shown in Figure 4. Growth at $600^{\circ} \mathrm{C}$ in $\mathrm{C}_{2} \mathrm{H}_{2}: \mathrm{H}_{2}: \mathrm{X}$ with $\mathrm{X}$ $=\mathrm{NH}_{3}$ (a) or $\mathrm{H}_{2} \mathrm{O}(\mathrm{b})$. The average cone angle $\theta$ is $39^{\circ}$ in the case of $\mathrm{NH}_{3}$ and $13^{\circ}$ in the case of $\mathrm{H}_{2} \mathrm{O}$ (see table I). (a) The inset shows how the graphitic planes follow the catalyst surface. (b) Image recorded in the [001] zone axis of the Ni particle (selected area electron diffraction pattern in inset), exhibiting $\{100\}$ facets.

\subsection{Capping of catalyst head}

Figure 6 compares a nanofibre grown in $\mathrm{H}_{2}: \mathrm{H}_{2} \mathrm{O}$ with one obtained in $\mathrm{NH}_{3}$, after dewetting in the same $\mathrm{H}_{2}: \mathrm{H}_{2} \mathrm{O}+\mathrm{C}_{2} \mathrm{H}_{2}$ mix. The growth conditions were the same in the two cases except for the nature of the etchant and a slightly higher growth temperature in the case of $\mathrm{H}_{2} \mathrm{O}\left(675{ }^{\circ} \mathrm{C}\right.$ instead of $\left.650{ }^{\circ} \mathrm{C}\right)$. It should be noted that the present micrographs (Figure 6) were taken after only a few tens of seconds of irradiation (see sec. 2.3), except Figure $6 \mathrm{f}$ which, recorded at a higher magnification, has undergone about 2 min of irradiation (in order to change the settings of the microscope), which started to break the surface film and oxidise the nickel. Still, one can see that the $\mathrm{NH}_{3}$-etched particle (Figure 6 f) is covered by a $\sim 2-\mathrm{nm}$ 
Z. B. He et al., Nickel catalyst shape

thick, partially crystallized, carbonaceous layer, while the $\mathrm{H}_{2} \mathrm{O}$ particle appears protected by at most a single monolayer of an undefined film.

\subsection{Tail of catalyst particle}

Using water vapour or ammonia has a dramatic effect on the shape of the conical tail of catalyst particles: we have measured that parameter for the two samples shown in Figure 4 and Figure 5, where all growth conditions were the same except for the etchant gas $\mathrm{X}: 600^{\circ} \mathrm{C}$, 30 min, $\mathrm{C}_{2} \mathrm{H}_{2}: \mathrm{H}_{2}: X$. The measurements were performed on SEM and TEM micrographs and are summarised in Table 1.

Table 1: Cone angle in the case of growth in $\mathrm{C}_{2} \mathrm{H}_{2}: \mathrm{H}_{2}: \mathrm{X}$, where $\mathrm{X}=\mathrm{H}_{2} \mathrm{O}$ or $\mathrm{NH}_{3}$, at $600^{\circ} \mathrm{C}$ for $30 \mathrm{~min}$.

\begin{tabular}{|l|c|c|c|}
\hline & Number of Ni & Average cone angle $\theta$ & Standard deviation \\
particles measured & (degrees) & \\
\hline $\mathrm{H}_{2} \mathrm{O}$ & 88 & 12.6 & 2.6 \\
\hline $\mathrm{NH}_{3}$ & 40 & 39.0 & 12.1 \\
\hline
\end{tabular}

The cone angle appears three times smaller in the case of water $\left(\theta \sim 13^{\circ}\right)$ than in that of ammonia $\left(\theta \sim 39^{\circ}\right)$. We confirm its decrease with growth temperature [11], so that the difference between the two etchants decreases as the temperature increases. A qualitative illustration of the smaller angle at $675^{\circ} \mathrm{C}$ for water and $650^{\circ} \mathrm{C}$ for ammonia is given by Figure 6a and d, respectively. 
Z. B. He et al., Nickel catalyst shape
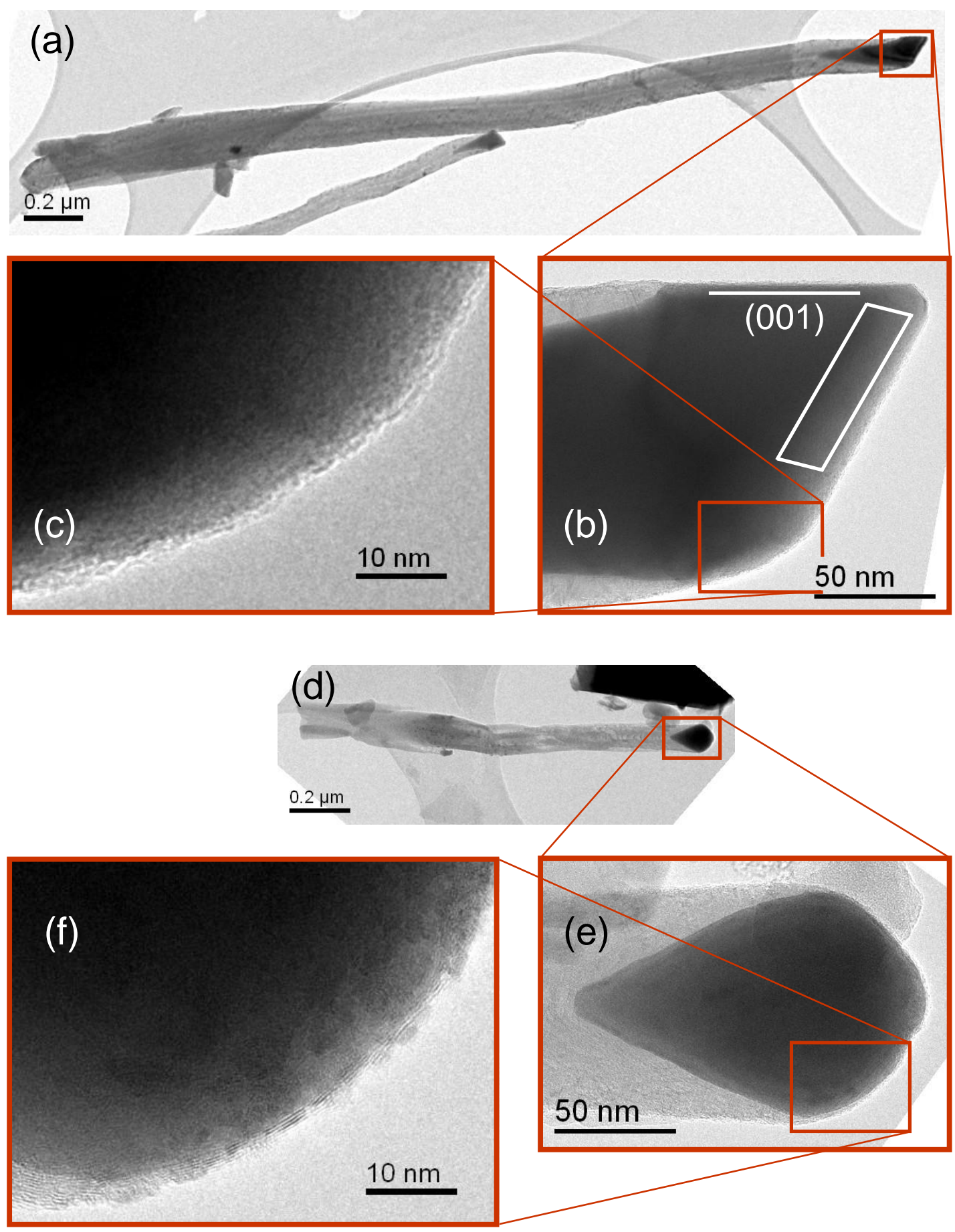

Figure 6. TEM images of CNFs with Ni catalyst particles on top, grown with a $\mathrm{H}_{2}: \mathrm{H}_{2} \mathrm{O}$ etchant at $675^{\circ} \mathrm{C}(\mathrm{a}-\mathrm{c})$ and $\mathrm{NH}_{3}$ at $650^{\circ} \mathrm{C}(\mathrm{d}-\mathrm{f})$. Note the faceting with sharp edges in the case of $\mathrm{H}_{2} \mathrm{O}$, absent in the case of $\mathrm{NH}_{3}$, and the presence of a film that caps the catalyst in the latter (f), partially crystallized in the form of graphene layers. 
Z. B. He et al., Nickel catalyst shape
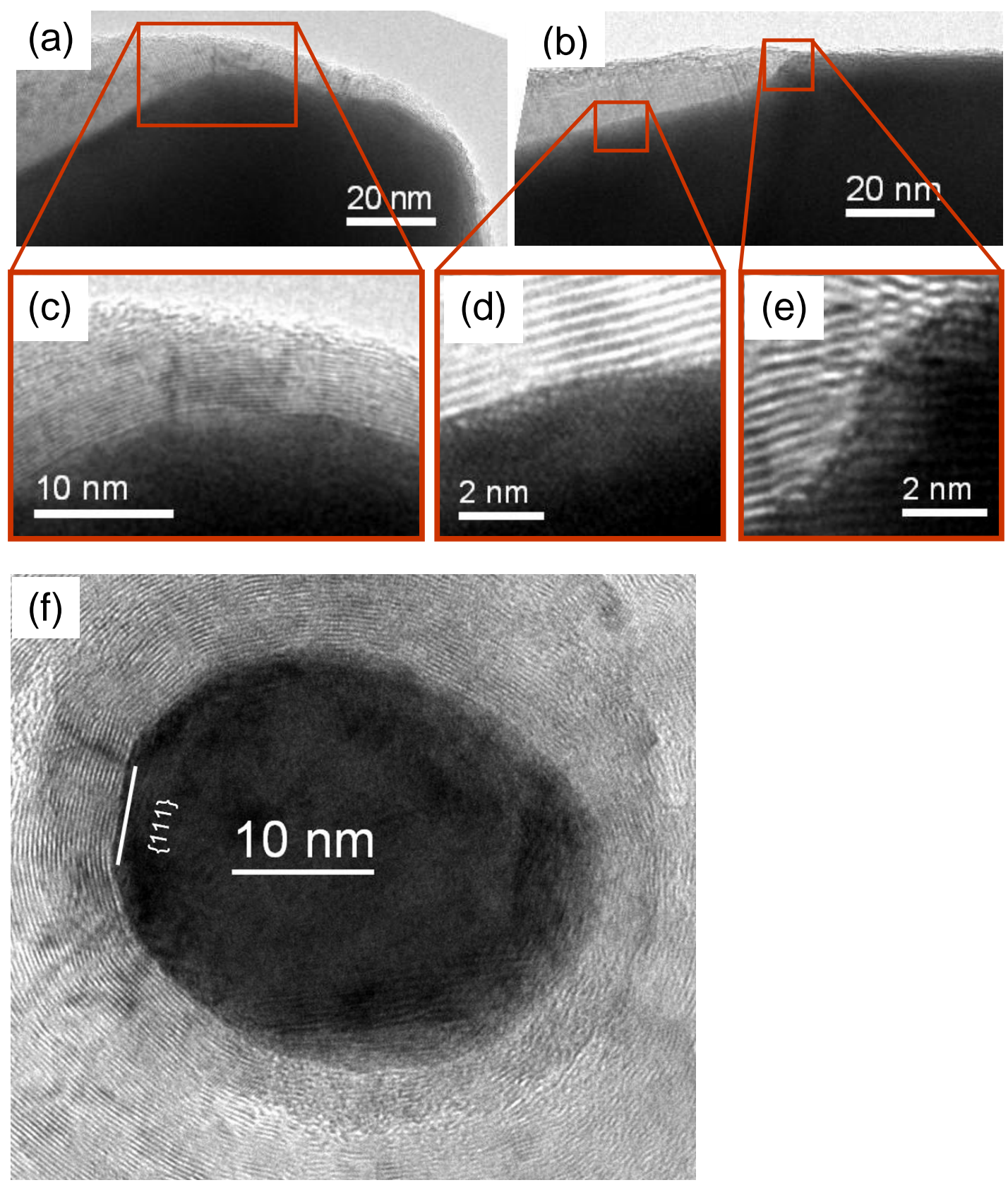

Figure 7. (a-d) Longitudinal views of catalysts in the case where ammonia (a, c) and hydrogen-water (b, d-f) were used as etchants (same deposits as those shown in Figure 6). Except at the limit between head and tail (b, e) where shoulders may exist, graphene planes stay parallel to the catalyst surface, whatever its shape or its density of steps. (f) Nanofibre embedded into glue, seen on end, in a horizontal cross-section. The interface between the tail of the catalyst particle and the nanofibre walls is smooth with no facet, except for a small planar $\{111\}$ section. 
Z. B. He et al., Nickel catalyst shape

Another remarkable feature of the catalyst tail is its apparent absence of faceting regardless of the gases used for growth (Figure 7). To confirm this observation, we prepared a few TEM cross-sections with in-plane nanofibres embedded into glue, where some of the nanoparticles had their head cut off during sample thinning, allowing one to watch their tail surrounded by the nanofibre walls in a "horizontal" cross-section (Figure 7f). In such crosssections, the interface can be seen in another angle, confirming the quasi absence of faceting: the catalyst tail is indeed, to a very good approximation, a truncated cone.

To summarise all our observations, the differences of catalyst shape between the two cases of etchants are thus striking. The catalyst tail has the shape of truncated non-faceted cone in both cases; but the cone angle drastically depends on the etchant used: $\theta \sim 39^{\circ}$ at the growth temperature of $600^{\circ} \mathrm{C}$ in the case of ammonia, and $\theta \sim 13^{\circ}$ in the case of water in the same conditions. The catalyst appears correlatively rounded and covered by a few layers of partially crystallised graphene layers in the case of $\mathrm{NH}_{3}$, while it looks sharply facetted and almost bare in the case of $\mathrm{H}_{2} \mathrm{O}$.

\section{Discussion: shape of Ni catalysts}

\subsection{Tail shape and graphene generation}

Let us first discuss the epitaxial relationships between the Ni catalyst and the graphene layers. Yang and Chen showed in their pioneering study [10] that the epitaxy of graphite should be favoured on the $\{111\}$ and $\{311\}$ facets of nickel. The $\{111\}$ surface of Ni had already been singled out more than three decades ago by the observation that it promoted the epitaxial growth of graphene [33]. This specificity of the $\mathrm{Ni}\{111\}$ face regarding the epitaxy of graphene layers stems of course from the same six-fold symmetry, but also from the additional fact that the parameter mismatch then remains small: $\Delta a / a=1.2 \%$ when $\mathrm{Ni}\langle 110\rangle$ 
Z. B. He et al., Nickel catalyst shape

atomic rows are parallel to $\mathrm{C}<100>$. However with the present observations of a conical growth surface, one sees that assuming given specific low-index planes of nickel to model epitaxy is an over-simplification. Although $\{111\}$ facets may develop at the interface, they are certainly not representative of the general phenomena that are responsible for the observed growth (see Figure 7).

We thus find that the interface between $\mathrm{Ni}$ and the graphene layers is conical in such a way that nickel presents a high density of vertical as well as horizontal atomic steps. Quite remarkably, the graphene layers remain parallel to that surface, thus following its conical shape, which actually determines the conical shape of the carbon $\{002\}$ planes in the nanofibre. Most Ni surface steps thus correspond to no additional graphene layer, as if the most general way of nucleation of the latter had been with a whole conical layer at a time (Figure 7a).

Existing models of graphene layer nucleation and growth have developed thanks to insitu TEM $[14,15,17,16,34]$. They often involve growth of several graphite planes at a time, almost perpendicularly to a catalyst surface. Such a mechanism may well occur here when shoulders exist between catalyst head and tail (Figure 7b). But those shoulders are no general features of the present particles: they are not found in all particles in the case of growth in hydrogen-water, and they are even less frequent in the case of growth in ammonia. On the other hand Helveg et al. have also observed a step edge mechanism of generation of a graphene plane, by scanning of a Ni single surface step [15, 35]. A similar mechanism probably takes place here, but with nickel "steps" which must be complicated objects that involve more than a monolayer of $\mathrm{Ni}$, and that follow the rounded topology of the conical tail. 

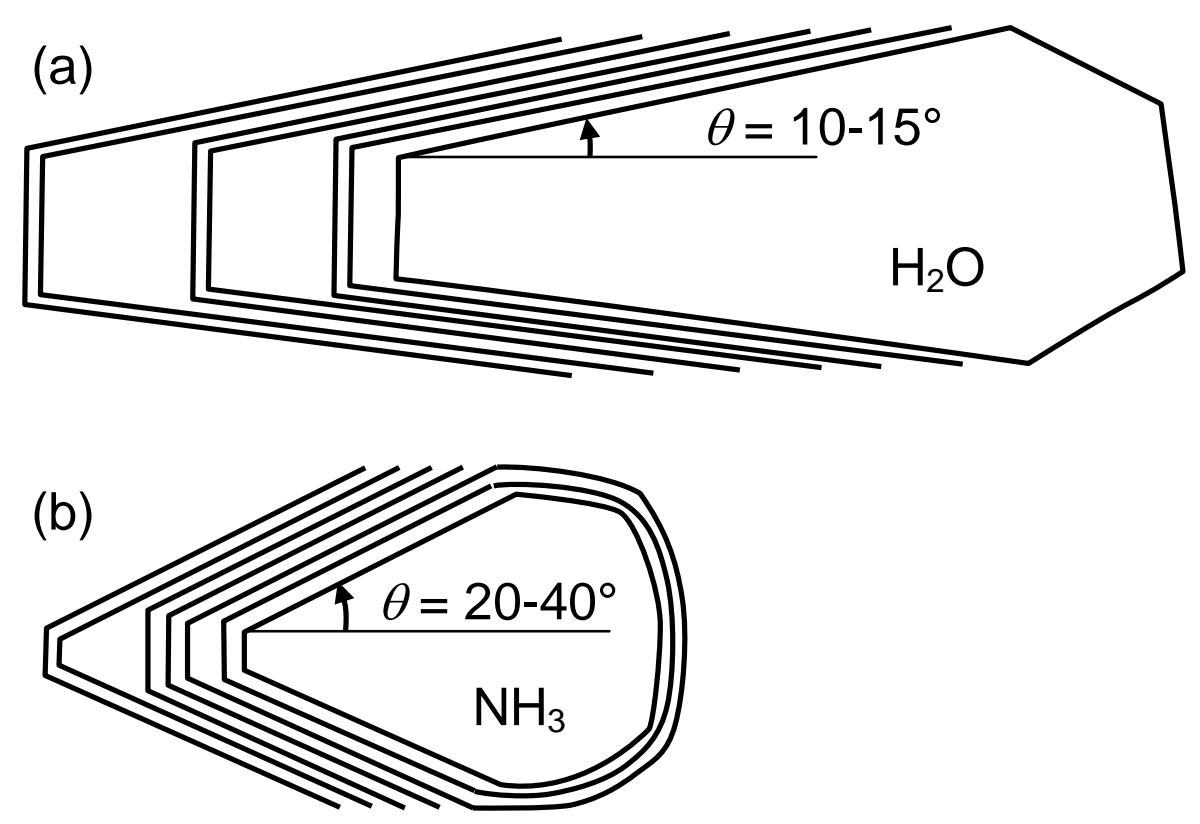

Figure 8. Schematic of the typical catalyst shape in the case of water (a) and in the case of ammonia (b). A range is given for cone angles to recall their dependence on temperature $(\theta$ decreases as $T$ increases). Note the differences in faceting of the head and in cone angle. The latter difference provokes a quite large difference in the vertical density of the graphene planes, which translates itself into a quite significant difference in nanofibre length. Water allows one to obtain the same length as a given ammonia-grown nanofibre with much less graphene layers.

However, it is important to note that the cone angle of the graphene sheets, $\theta$, is radically smaller in the case of water than in that of ammonia: $13^{\circ}$ vs. $39^{\circ}$ at $600^{\circ} \mathrm{C}$ (Table I). This indicates that the same length of nanofibre includes a lower number of graphene sheets in the case of water than in that of ammonia, or else, that a same number of cone-shaped layers delivers a larger length of nanofibre in the former case than in the latter (Figure 8).

There is a direct relationship between those observations and the fact that the growth rate is indeed faster with the water etchant. But is it the high rate that forces the graphene layers to 
Z. B. He et al., Nickel catalyst shape

be more tubular, and in turn the Ni particle to get elongated, or is it the elongated shape of the particle that is the origin of the high growth rate? We propose in the following that it be the particle that would determine the change of shape, due to an increased rate of transfer of carbon atoms in the case of water compared to that of ammonia.

\subsection{Faceting}

Literature presents various results on surface structure and surface capping that reflect the variety of growth conditions used. In the case of the $\mathrm{NH}_{3}$ etchant, the seminal work of Chhowalla et al. [4] already showed that the top, free part of the catalyst particles, was covered by a carbon film, and that, if some facets could be visible, such features had rounded edges. Our observations are thus a confirmation of the smoothing effect of $\mathrm{NH}_{3}$ on the shape of catalyst particles.

In the case of water, the faceting we observe seems to be specific of our growth conditions: PE-CVD, $600-670^{\circ} \mathrm{C}$, large amounts of $\mathrm{H}_{2} \mathrm{O}$ in the gas mixture, as indeed, the faceting appearing after other growth conditions has quite different characteristics. Audier et al. were the first to study faceting in detail [22]; they concluded that in the case of fcc metals, only $\{111\}$ facets could be observed: their growth method was based on the catalytic disproportionation of $\mathrm{CO}$ at $P=1 \mathrm{~atm}$ and $450{ }^{\circ} \mathrm{C}<T<650{ }^{\circ} \mathrm{C}$ [22]. In contrast, Kuang et al., who worked at a pressure of $3 \mathrm{kPa}(30 \mathrm{mbar})$ with a mix of $\mathrm{N}_{2}: \mathrm{H}_{2}: \mathrm{CH}_{4}$, found that $\mathrm{Ni}$ particles had $<110>$ orientation and $\{110\}$ top facets [23]. These authors used a hot-wire PE-CVD equipment, at $T=700{ }^{\circ} \mathrm{C}$. Yang and Chen, who performed growth using a similar gas mix at a pressure of 1 atm [10], reported that $\{110\}$ faces were catalytically active for the dissociation of $\mathrm{CH}_{4}$, while $\{111\}$ were not.

Here for the top part of the catalytic particles, we found only few $\{110\}$ oriented facets, many $\{111\}$, and many $\{100\}$. Thus we cannot conclude like in previous works that a given 
Z. B. He et al., Nickel catalyst shape

surface orientation is dominating, but only that low-energy surfaces prevail, perhaps just indicating that the catalyst surfaces remain almost bare during catalysis, so that they adopt a configuration close to the equilibrium one, as in a Wulff polyhedron [36]. The sharp edges sometimes visible (e.g. Figure 6) are faceted themselves at a lower scale (Figure 6b) which indicates that the top catalyst surfaces in the case of $\mathrm{H}_{2} \mathrm{O}$ etchant are close indeed to thermal equilibrium.

\subsection{Capping of the head and carbon diffusion}

The activation energies found for the growth rates are lower in the case of water $(0.18$ $\mathrm{eV})$ [37], than in the case of ammonia $(0.23 \mathrm{eV})$ [38]. In both cases, the conclusion was that diffusion was a surface phenomenon. Thus, we are tempted to say that, for the present comparisons, the difference stems from the nickel catalytic activity, which would have been larger at the bare metal surfaces of the water case, than at the surfaces covered by a $2-\mathrm{nm}$ carbon film of the ammonia case. But we must keep in mind that the present results were obtained after completed growth, and thus do not represent the state of the catalyst surface during growth. The surface graphene layers in the case of ammonia may also have built up after growth indeed; as carbon must have penetrated into nickel during growth up to its solubility limit at the growth temperature, and it must have precipitated at the surfaces after the decrease of solubility upon cooling [39].

Reciprocally, graphene layers should have appeared on the surface upon cooling if the solubility was attained during growth. Thus, an absence of visible graphene layers as in the present case of water etchant would indicate that the carbon concentration has not reached the solubility limit during deposition. Thus diffusion would be a pure surface phenomenon in that case while it would include a bulk component in the ammonia case. 
Z. B. He et al., Nickel catalyst shape

Finally, in-situ, environmental TEM $[15,40]$ would be the only way: to determine the time at which the surface layers have built up; and thus to allow one to conclude on the origin of the differences in the activation energy and rate of the growth.

\section{Conclusions}

Vertically aligned CNFs were grown by the tip-growth mechanism, using dc PECVD in the $600-670^{\circ} \mathrm{C}$ temperature range and using different gas precursors. We compared the effects of etchants based on $\mathrm{H}_{2} \mathrm{O}$ and $\mathrm{NH}_{3}$ on the shape of the catalytic Ni particles. The water-based mixtures appeared to provide faster growth with lower cone angle. The top catalyst surfaces were in that case bare and sharply faceted, which contrasted with the rounded surfaces of the $\mathrm{NH}_{3}$-treated samples which were capped with a 2-nm thick, partially crystallised, graphenelike film. The exposed surfaces of the Ni particles at the growth front were a combination of low index facets such as $\{111\}$ and $\{100\}$, as in a Wulff polyhedron, rather than a unique type of facet such as $\{111\}$ [22] or $\{110\}$ [23]. We associate the lower cone angle and higher growth rate of water-etched nanofibres with faster diffusion of carbon atoms across their bare top surfaces.

\section{ACKNOWLEDGEMENTS}

ZBH thanks Dr. G. Rizza and F. Attouchi at Laboratoire des Solides Irradiés, Ecole Polytechnique, France for useful discussions. JLM is grateful to Dr. G. Garry and Dr. S. Enouz-Vedrenne (Thales Research and Technology France) for access to the Topcon 002B. DP would like to acknowledge partial support from WCU program, through the NRF of Korea, funded by MEST (R31-2008-000-10029-0). This work has been supported by the Region Ile-de-France in the framework of C'Nano IdF. C'Nano IdF is the nanoscience 
Z. B. He et al., Nickel catalyst shape

competence center of Paris Region, supported by CNRS, CEA, MESR and Region Ile-deFrance. 
Z. B. He et al., Nickel catalyst shape

\section{References}

[1] Heer WA, Chatelain A, Ugarte D. A carbon nanotube field-emission electron source. Science 1995;270(5239):1179-80.

[2] Fan S, Chapline MG, Franklin NR, Tombler TW, Cassell AM, Dai H. Self-oriented regular arrays of carbon nanotubes and their field emission properties. Science 1999;283(5401):512-4.

[3] Tsai TY, Lee CY, Tai NH, Tuan WH. Transfer of patterned vertically aligned carbon nanotubes onto plastic substrates for flexible electronics and field emission devices. Appl Phys Lett 2009;95(1):013107.

[4] Chhowalla M, Teo KBK, Ducati C, Rupesinghe NL, Amaratunga GAJ, Ferrari AC, et al. Growth process conditions of vertically aligned carbon nanotubes using plasma enhanced chemical vapor deposition. J Appl Phys 2001;90(10):5308-17.

[5] Teo KBK, Minoux E, Hudanski L, Peauger F, Schnell J-P, Gangloff L, et al. Carbon nanotubes as cold cathodes. Nature 2005;437:968.

[6] Meyyappan M, Delzeit L, Cassell A, Hash D. Carbon nanotube growth by PECVD: a review. Plasma Sources Sci Technol 2003;12(2):205-16.

[7] Melechko AV, Merkulov VI, McKnight TE, Guillorn MA, Klein KL, Lowndes DH, et al. Vertically aligned carbon nanofibers and related structures: Controlled synthesis and directed assembly. J Appl Phys 2005;97(4):041301-39.

[8] Teo KBK, Chhowalla M, Amaratunga GAJ, Milne WI, Hasko DG, Pirio G, et al. Uniform patterned growth of carbon nanotubes without surface carbon. Appl Phys Lett 2001;79:153436. 
Z. B. He et al., Nickel catalyst shape

[9] Kukovitsky EF, L’vov SG, Sainov NA, Shustov VA, Chernozatonskii LA, Correlation between metal catalyst particle size and carbon nanotube growth. Chem Phys Lett 2002; 355(5-6):497-503.

[10] Yang RT, Chen JP. Mechanism of carbon filament growth on metal catalysts. J Catal 1989;115(1):52-64.

[11] Tracz E, Scholz R, Borowiecki T, High-resolution electron microscopy study of the carbon deposit morphology on nickel catalysts. Applied Catalysis 1990;66(1):133-147.

[12] Nolan PE, Schabel MJ, Lynch DC, Cutler AH, Hydrogen control of carbon deposit morphology. Carbon 1995;33(1):79-85.

[13] Kiselev NA, Hutchison JL, Moravsky AP, Rakova EV, Dreval EV, Hetherington CJD, et al. Carbon micro- and nanotubes synthesized by PE-CVD technique: Tube structure and catalytic particles crystallography. Carbon 2004;42(1):149-161.

[14] Sun L, Banhart F, Krasheninnikov AV, Rodriguez-Manzo JA, Terrones M, Ajayan PM. Carbon nanotubes as high-pressure cylinders and nanoextruders, Science 2006; 312: 11991202.

[15] Helveg S, Lopez-Cartes C, Sehested J, Hansen PL, Clausen BS, Rostrup-Nielsen R, et al. Atomic-scale imaging of carbon nanofibre growth. Nature 2004; 427(6973):426-9.

[16] Hofmann S, Sharma R, Ducati C, Du G, Mattevi C, Cepek C, Cantoro M, Pisana S, Parvez A, Cervantes-Sodi F, Ferrari AC, Dunin-Borkowski R, Lizzit S, Petaccia L, Goldoni A, Robertson J, In situ observations of catalyst dynamics during surface-bound carbon nanotube nucleation, Nano Lett 2007; 7(3):602-608.

[17] Lin M, Tan JPY, Boothroyd C, Loh KP, Tok ES, Foo YL, Dynamical observation of bamboo-like carbon nanotube growth, Nano Lett 2007;7(8): 2234-2238. 
Z. B. He et al., Nickel catalyst shape

[18] Kunadian I, Andrews R, Qian D, Mengüç MP. Growth kinetics of MWCNTs synthesized by a continuous-feed CVD method Carbon 2009;47(2):384-95.

[19] Ichihashi T, Fujita J-I, Ishida M, Ochiai Y. In situ observation of carbon-nanopillar tubulization caused by liquid like iron particles. Phys Rev Lett 2004;92(21):215702. [20] Yoshida H, Takeda S, Uchiyama T, Kohno H, Homma Y. Atomic-scale in-situ observation of carbon nanotube growth from solid state iron carbide nanoparticles. Nano Lett 2008;8(7):2082-6.

[21] Ignacio M-G, José V, Juan AC, José LG, César M. Differences between carbon nanofibers produced using $\mathrm{Fe}$ and Ni catalysts in a floating catalyst reactor. Carbon 2006;44(8):1572-80.

[22] Audier M, Oberlin A, Coulon M. Crystallographic orientations of catalytic particles in filamentous carbon; Case of simple conical particles. J Cryst Growth 1981;55(3):549-56. [23] Kuang MH, Wang ZL, Bai XD, Guo JD, Wang EG. Catalytically active nickel $\{110\}$ surfaces in growth of carbon tubular structures. Appl Phys Lett 2000;76(10):1255-57. [24] Esconjauregui S, Whelan CM, Maex K. The reasons why metals catalyze the nucleation and growth of carbon nanotubes and other carbon nanomorphologies. Carbon 2009;47(3):659-69.

[25] Dupuis A-C. The catalyst in the CCVD of carbon nanotubes - a review. Progr Mat Sci 2005; 50(8): 929-61.

[26] Hata K, Futaba DN, Mizuno K, Namai T, Yumura M, Iijima S. Water-assisted highly efficient synthesis of impurity-free single-walled carbon nanotubes. Science 2004;306(5700): $1362-4$.

[27] Murayama H, Maeda T. A novel form of filamentous graphite. Nature 1990; 345 (6278): 791-3. 
Z. B. He et al., Nickel catalyst shape

[28] Nolan PE, Lynch DC, Cutler AH. Carbon deposition and hydrocarbon formation on group VIII metal catalysts. J Phys Chem B 1998; 102(21):4165-75.

[29] Hofmann S, Kleinsorge B, Ducati C, Ferrari AC, Robertson J, Low-temperature plasma enhanced chemical vapour deposition of carbon nanotubes. Diamond and Related Materials 2004; $13: 1171-1176$.

[30] Smith B. W., Luzzi D. E. Electron irradiation effects in single wall carbon nanotubes. J. Appl. Phys. 2001; 90(7): 3509-16.

[31] He ZB, Maurice J-L, Lee CS, Pribat D, Cojocaru CS, to appear in the Arabian Journal for Science and Engineering, Theme Issue on "Science and Engineering at the Nanoscale". [32] Cojocaru CS, Kim D, Pribat D, Bourée J-E. Synthesis of multi-walled carbon nanotubes by combining hot-wire and dc plasma-enhanced chemical vapor deposition.Thin Solid Films 2006;501(1-2):227-32.

[33] Eizenberg M, Blakely JM. Carbon monolayer phase condensation on Ni(111). Surf Sci $1979 ; 82: 228-36$.

[34] Rodriguez-Manzo JA, Terrones M, Terrones H, Kroto HW, Sun L, Banhart F. In situ nucleation of carbon nanotubes by the injection of carbon atoms into metal particles. Nature Nano 2007;2(5):307-11.

[35] Abild-Pedersen F, Nørskov JK, Rostrup-Nielsen JR, Sehested J, Helveg S. Mechanisms for catalytic carbon nanofiber growth studied by ab initio density functional theory calculations. Phys Rev B 2006; 73(11):115419.

[36] For a demonstration of Wulff theorem, see e.g., Müller P, Kern R. Equilibrium nanoshape changes induced by epitaxial stress (generalised Wulf-Kaishew theorem). Surf Sci 2000; 457(1-2):229-53. 
Z. B. He et al., Nickel catalyst shape

[37] Cojocaru CS et al. Water based PECVD process for the growth of oriented and patterned carbon nanotubes. Submitted to ACS Nano.

[38] Hofmann S, Csányi G, Ferrari AC, Payne MC, Robertson J. Surface diffusion: the low activation energy path for nanotube growth. Phys Rev Lett 2005;95:036101.

[39] Lander JJ, Kern HE, Beach AL. Solubility and diffusion coefficient of carbon in nickel: reaction rates of nickel-carbon alloys with barium oxide. J. Appl. Phys. 1952; 23(12): 130508.

[40] Giorgio S, Sao Joao S, Nitsche S, Chaudanson D, Sitja G, Henry CR. Environmental electron microscopy (ETEM) for catalysts with a closed E-cell with carbon windows.

Ultramicroscopy 2007;106(6):503-7. 